\title{
HOXA9 is a novel myopia risk gene
}

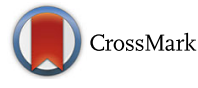

\author{
Chung-Ling Liang ${ }^{1,2,3,4}$, Po-Yuan Hsu ${ }^{3}$, Cheryl S. Ngo ${ }^{5}$, Wei Jie Seow ${ }^{6}$, Neerja Karnani ${ }^{7}$, Hong Pan ${ }^{7}$, \\ Seang-Mei Saw ${ }^{6,8}$ and Suh-Hang H. Juo $0^{3,9,10,11,12^{*} \text { (iD }}$
}

\begin{abstract}
Purpose: A recent meta-analysis revealed PAX6 as a risk gene for myopia. There is a link between PAX6 and HOXA9. Furthermore, HOXA9 has been reported to activate TGF- $\beta$ that is a risk factor for myopia. We speculate HOXA9 may participate in myopia development.

Methods: The Singapore GUSTO birth cohort provides data on children's cycloplegic refraction measured at age of 3 years and their methylation profile based on the umbilical cord DNA. The HOXA9 expression levels were measured in the eyes of mono-ocular form deprivation myopia in mice. The plasmid with the mouse HOXA9 CDNA was constructed and then transfected to mouse primary retinal pigment epithelial (RPE) cells. The expression levels of myopia-related genes and cell proliferation were measured in the HOXA9-overexpressed RPE cells.

Results: A total of 519 children had data on methylation profile and cycloplegic refraction. The mean spherical equivalent refraction (SE) was 0.90D. Among 8 SE outliers (worse than -2D), 7 children had HOXA9 hypomethylation. The HOXA9 levels in the retina of myopic eyes was 2.65-fold ( $p=0.029$; paired t-test) higher than the uncovered fellow eyes. When HOXA9 was over-expressed in the RPE cells, TGF- $\beta$, MMP2, FGF2 and IGF1R expression levels were dose-dependently increased by HOXA9. However, over-expression of HOXA9 had no significant influence on IGF1 or HGF expression. In addition, HOXA9 also increased RPE proliferation.
\end{abstract}

Conclusion: Based on the human, animal and cellular data, the transcription factor HOXA9 may promote the expression of pro-myopia genes and RPE proliferation, which eventually contribute to myopia development.

Keywords: HOXA9, PAX6, microRNA-328, Myopia

\section{Introduction}

Myopia is a common eye condition worldwide, and its prevalence varies widely among populations and ages [1-3]. Both genetic and environmental factors contribute to the development of myopia [4]. Several myopia susceptibility genes have been reported based on genetic association studies as well as gene expression studies [5-7]. Recently, data from meta-analysis of genome-wide association studies further reported newly identified genetic loci [8-10]. On the other hand, several environmental risk factors were reported to be associated with myopia. Outdoor activity is demonstrated to be a protective factor against myopia onset and progression in school children [11-13]. Furthermore, meta-analysis also provides evidence to

\footnotetext{
*Correspondence: hjuo@mail.cmu.edu.tw

${ }^{3}$ Center for Myopia and Eye Disease, Department of Medical Research, China Medical University Hospital, Taichung, Taiwan

9The Ophthalmology \& Visual Sciences Academic Clinical Program,

DUKE-NUS Graduate Medical School, Singapore, Singapore

Full list of author information is available at the end of the article
}

support that the interaction between genetic and environmental factors contributes to myopia development [14].

We previously reported that microRNA-328 (miR-328) can bind to PAX6 mRNA and negatively regulate PAX6 expression, which leads to myopia development $[2,15]$. A recent meta-analysis revealed $P A X 6$ as a myopia risk gene [16]. MEIS1 is a transcription factor that regulates the retina [17-19] and lens development [20,21]. It has been shown that PAX6 and MEIS1 can simultaneously regulate eye development [20]. On the other hand, MEIS1 can form a complex with HOXA9 in myeloid cells [22]. HOXA9 can transcriptionally activate transforming growth factor- $\beta$ (TGF- $\beta$ ) [23] and TGF- $\beta$ signaling has long been implied as a risk factor for myopia [24]. All these three genes (PAX6, MEIS1 and HOXA9) are homeobox genes. In addition, our methylation profiles of genomic DNA showed aberrant methylation at HOXA9 in myopia of preschool children (see details in the Result section). Although there has been no report

(c) The Author(s). 2019 Open Access This article is distributed under the terms of the Creative Commons Attribution 4.0 International License (http://creativecommons.org/licenses/by/4.0/), which permits unrestricted use, distribution, and reproduction in any medium, provided you give appropriate credit to the original author(s) and the source, provide a link to the Creative Commons license, and indicate if changes were made. The Creative Commons Public Domain Dedication waiver (http://creativecommons.org/publicdomain/zero/1.0/) applies to the data made available in this article, unless otherwise stated. 
regarding the role of $H O X A 9$ gene in any eye diseases or myopia, we speculate HOXA9 may participate in myopia development because of the aforementioned findings. In the present study, we investigated the effects of HOXA9 on myopia using human, animal and cellular samples.

\section{Method}

\section{Human studies}

\section{DNA methylation study}

We used the data collected from the GUSTO birth cohort, which was previously described [25]. Children with any known or determined eye conditions including strabismus, eye infection, eye injury, facial nerve palsy, developmental anomaly and other such eye related conditions were not included. The National Health Group's Domain Specific Review Board and the SingHealth Centralized Institutional Review Board approved this study. The parents or legal guardians gave informed written consent. The present study was conducted according to the tenets of the Declaration of Helsinki.

Genomic DNA was extracted from infant umbilical cords of GUSTO samples collected at birth and was profiled using the Infinium Human Methylation450 BeadChip arrays. The details of methylation profiling can be found in our previous publication [26]. Data were processed by signal correction and adjustment for different color channels as described by Pan et al. [27]. A total of 160,418 CpGs of the 519 subjects were finally used for further analysis [26-29].

\section{Eye measurements performed at 3 years old}

Out of 1236 recruited participants, 925 children (74.8\%) attended the third year clinic visit. Axial length (AXL) was measured in 764 children (61.5\%), and a cycloplegic refraction was performed in 574 children (46.3\%). Cycloplegic autorefraction was performed with a table-mounted autorefractor (Model RK-F1; Canon, Tokyo, Japan). Spherical equivalent refraction (SE) for each eye was calculated as sphere power plus half cylinder power. We used data from right eyes only, due to the high correlation between the right and left eyes (Spearman rho: 0.88 for SE and 0.96 for AXL). Myopia was defined as a SE of at least -0.5 diopter (D). The analysis was based on 519 children who had data on methylation profile and cycloplegic refraction.

\section{Animal studies}

\section{FDM mice and measure of ocular axial length}

We used a well-documented method to induce mono-ocular form deprivation myopia (FDM) in mice [30]. The C57BL/6J mice were purchased from the $\mathrm{Na}-$ tional Laboratory Animal Center, Taiwan. Mice were maintained in a temperature-controlled $\left(25^{\circ} \mathrm{C}\right)$ facility with a strict $12 \mathrm{~h}: 12 \mathrm{~h}$ light: dark cycle. The right eyes of mice were covered from age of 23 days to 51 days (i.e. covered for 4 weeks) to induce myopia, while the left eyes were uncovered. All the animals were euthanized on day 51 mice by using an overdose of isoflurane anesthesia, and both eyes were dissected for AXL measurement. To euthanize the mice, animals were placed into clear, plastic cages. When the mice were added to the cage, isoflurane (Attane ${ }^{\mathrm{Tw}}$, Panion \& BF Biotech Inc., Taiwan) was applied to the absorbent paper towels that were in the cage, and the cage was immediately sealed. The operator continuously monitored the mice for their respiration, color, and movement. If a mouse showed loss of consciousness, respiratory arrest and no heart beat by direct cardiac palpation, we confirmed that a mouse had died.

In order to reduce human errors and bias while measuring AXL, we developed a software to automatically calculate the AXL of dissected eyes. First, a pair of dissected eyes was placed on a slide for photo picture under a dissecting microscope. Then the K-means clustering algorithm was employed to separate the eyes from the background matrix to obtain a cleaned image. Finally, the software split the two eyes into two contours, and the ellipse fitting algorithm is used to fit on both contours. The contour's longest vertical line is defined as the AXL.

The animal care guidelines are comparable with those published by the Institute for Laboratory Animal Research (NIH Publications No 8023, revised 1978). The animal research in this study was approved by the Animal Care and Ethics Committee at China Medical University, Taiwan.

\section{Cellular studies}

\section{Human retinal pigment epithelial cell culture}

The human retinal pigment epithelial (ARPE-19) cell line was obtained from Bioresource Collection and Research Center (BCRC) (Hsinchu, Taiwan) which derived from American Type Culture Collection (ATCC, Manassas, VA; ATCC number: CRL-2302). ARPE-19 cells were cultured in DMEM/F12 medium (Gibco-BRL, Gaithersburg, MD) supplemented with 10\% FBS (Gibco-BRL), 50 units $/ \mathrm{mL}$ penicillin, and $50 \mathrm{mg} / \mathrm{mL}$ streptomycin. The cells were seeded on a 12 -well plate $\left(10^{5}\right.$ cells/well $)$ and were transfected with miR-328 by HiPerfect transfection reagent (Qiagen, Valencia, California, USA). Four hours after transfection, cells were changed into normal culture medium.

\section{Mouse primary RPE cell}

Eyes were dissected from male C57BL/6J mice aged 610 weeks. The dissected eye was incised from the optic nerve insertion site to remove lens, retina and cornea without disrupting the underlying retinal pigmented epithelium. The left behind RPE/choroid-sclera complex 
was placed in digestion buffer $0.25 \%$ trypsin in DMEM for $1 \mathrm{~h}$ at $37^{\circ} \mathrm{C}$ with gentle digestion. FBS was added to the tissue to terminate the digestion, and then the tissue was washed twice with $1 \mathrm{x}$ PBS and subject to centrifuge (1500 rpm, $5 \mathrm{~min}$ at $4{ }^{\circ} \mathrm{C}$ ). After removal of the supernatant, culture medium was added to the tube and RPE cells were cultured in incubator at $37^{\circ} \mathrm{C}$. RPE culture medium contained N2 supplement (Gibco) 1:100 mL/mL, penicillin-streptomycin (Sigma-Aldrich) $1: 100 \mathrm{~mL} / \mathrm{mL}$, nonessential amino acid solution (Sigma-Aldrich) 1:100 $\mathrm{mL} / \mathrm{mL}$, hydrocortisone $(20 \mu \mathrm{g} / \mathrm{L}$, Sigma-Aldrich), taurine (250 mg/L, Sigma-Aldrich), and triiodo-thyronin $(0.013 \mu \mathrm{g} /$ L, Sigma-Aldrich) with 5\% FBS [31]. To obtain single cells, the cells were grown on a gelatin pre-coated 24-well plate for $2 \mathrm{~h}$.

\section{Immunocytochemistry for mouse RPE cells}

Immunostaining was used to confirm that the isolated cells were the mouse RPE. For immunostaining, cells were fixed in $4 \%$ paraformaldehyde for $30 \mathrm{~min}$ and washed three times with cold PBS. The cells were permeabilized for 30 min with $0.1 \%$ Triton X-100-BSA. The cells were washed with PBS and blocked with BSA for $30 \mathrm{~min}$ at room temperature. Immunofluorescence staining was performed using anti-RPE-65 (1:200, Abcam, Cambridge, UK; catalog ab78036) [32] and anti-ZO-1 (1:200, Abcam; catalog ab59720) [33] antibodies according to manufacturer's guide. Cells were counterstained with 40, 6-diamidino-2-phenylindole (DAPI) to identify the nuclei.

\section{miRNA transfection}

The cells (ARPE-19 and mouse RPE) were seeded on a 12 -well plate $\left(10^{5}\right.$ cells/well $)$ and were transfected with different doses of miRNA-328 (1, 5, 10, 25 and $50 \mathrm{nM})$ or control miRNA by HiPerFect transfection reagent (Qiagen). Four hours after transfection, cells were changed into normal culture medium. After incubation for $24 \mathrm{~h}$, the cells were harvested and the lysates were utilized for protein detection to verify the efficacy of miRNA-328.

\section{Construction and transfection of HOXA9 CDNA}

HOXA9 (NP_034586.1) cDNA was cloned into the pIRES2-EGFP vector (BD Biosciences Clontech, Palo Alto, CA, USA) to form the construct of pIRES2-EGFP-HOXA9 plasmid. The plasmid was transformed into DH5 $\alpha$ competent cells and cultured overnight on a Luria broth agar plate containing kanamycin in a $37^{\circ} \mathrm{C}$ constant temperature incubator. Single colonies were picked from the plate, and plasmid DNA was extracted according to the manufacturer's protocol (QIAGEN). The sequences of constructs were confirmed by DNA sequencing. Cells below passage 10 were used in all experiments. To conduct the transfection experiments, mouse RPE cells were seeded on a 12-well plate at a density of $1 \times 10^{5}$ cells/well. After achieving $70 \%$ confluence in a well, pIRES2-EGFP or pIRES2-EGFP-HOXA9, was transfected with Lipofectamine 2000 (Invitrogen, Gaithersburg, MD, USA). After incubation for $24 \mathrm{~h}$, the cells were harvested, and the lysates were utilized for western blot to verify efficacy of HOXA9 overexpression in the mouse RPE cells.

\section{Cell viability assay}

The WST-1 reagent (diluted 1:10 in growth medium) was added for $2 \mathrm{~h}$ as described in the instruction manual (Roche, Mannheim, Germany). Viable cell mass was determined by the optical density measurement by a microplate reader at $450 \mathrm{~nm}$, using $600 \mathrm{~nm}$ as a reference wavelength.

\section{EdU proliferation assay}

To assess cell proliferation, the mouse primary RPE cells were seeded on a 12-well plate and then transfected with pIRES2-EGFP-HOXA9 by Lipofectamine 2000 (Invitrogen). Four hours after transfection, cells were changed into normal culture medium. Twenty-four hours after transfection, cell proliferation rate was detected using the incorporation of 5-ethynyl-29-deoxyuridine (EdU) with the Click-iT EdU Microplate Assay Kit (Thermo Scientific, Waltham, MA, USA). EdU incorporated into DNA was coupled to Oregon Green-azide and then detected using an HRP-conjugated anti-Oregon Green antibody and Amplex UltraRed. Fluorescence detected at an excitation/emission wavelength of $490 / 585 \mathrm{~nm}$ was taken as the cell proliferation rate.

\section{Real-time PCR, western blot}

Total RNA was extracted from ARPE-19 and mouse RPE using the TRIzol ${ }^{\circ}$ Reagent (Invitrogen). We used

Table 1 Primers used for quantitative real-time polymerase chain reaction

\begin{tabular}{ll}
\hline Gene & Primer \\
\hline HOXA9 F & 5'- CCC CGA CTT CAG TCC TTG C- 3' \\
HOXA9 R & 5'- GAT GCA CGT AGG GGT GGT G- 3' \\
PAX6 F & 5'- TAG CCC AGT ATA AAC GGG AGT G- 3' \\
PAX6 R & 5'- CCA GGT TGC GAA GAA CTC TG- 3' \\
MMP2 F & 5'- CAA GTT CCC CGG CGA TGT C- 3' \\
MMP9 R & 5'- TTC TGG TCA AGG TCA CCT GTC-3' \\
FGF2 F & 5'- GCG ACC CAC ACG TCA AAC TA-3' \\
FGF2 R & 5'- TCC CTT GAT AGA CAC AAC TCC TC-3' \\
IGF1R F & 5'- GAA GAA CGC CGA CCT CTG TTA- 3' \\
IGF1R R & 5'- GCA GCG ATT TGT GGT CCA G' \\
GAPDH F & 5'- TGA CCA CAG TCC ATG CCA TC-3' \\
GAPDH R & 5'- GAC GGA CAC ATT GGG GGT AG-3' \\
\hline
\end{tabular}




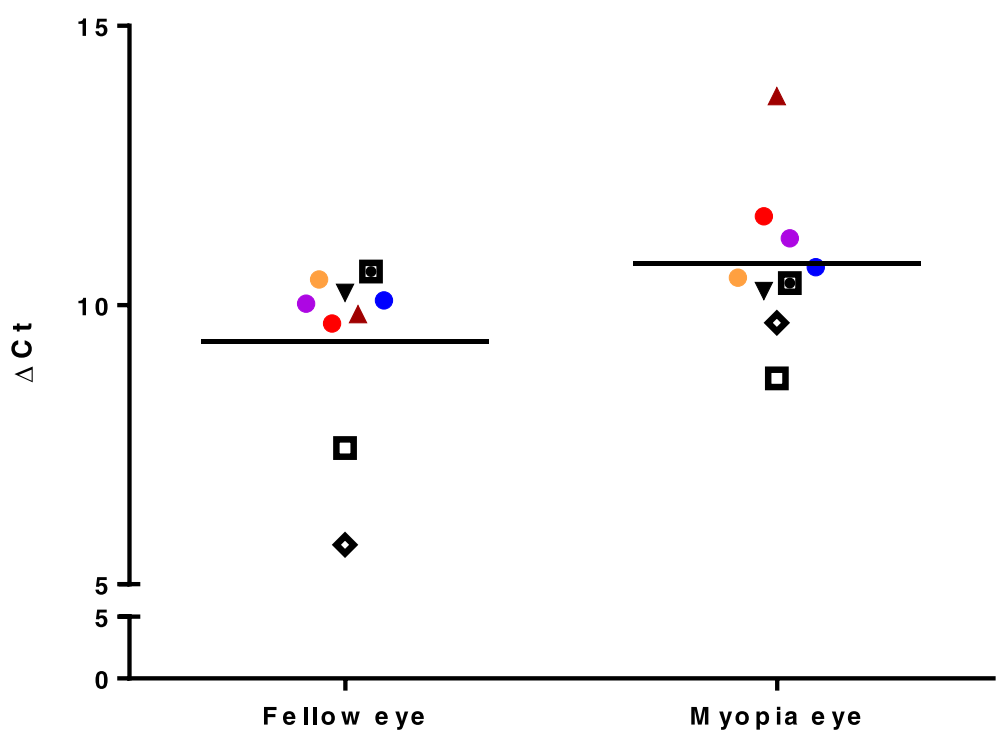

Fig. 1 An increase of HOXA9 expression level in the myopic eyes of FDM mice. HOXA9 RNA expression level was higher $(p=0.029)$ in the myopic eyes than the fellow normal eyes of FDM mice. The eyes from a same animal have the same color and shape in the figure

$1 \mu \mathrm{g}$ of starting mRNA (Applied Biosystems, Darmstadt, Germany) and random hexamers to create cDNA. The sequences of PCR primers are shown in Table 1. The relative amount of mRNA of interest was normalized to GAPDH. Real-time PCR was performed on an ABI StepOnePlus $^{\mathrm{mat}}$ Real-Time PCR Systems (Applied Biosystems) in duplicate using $5 \mu \mathrm{l} 2 \times$ SYBR Green qPCR Master Mix, $0.2 \mu \mathrm{l}$ primer sets, $1 \mu \mathrm{l}$ cDNA and $3.6 \mu \mathrm{l}$ nucleotide-free $\mathrm{H} 2 \mathrm{O}$, which yielded a $10 \mu \mathrm{l}$ reaction. The protein concentrations were determined by using the Pierce BCA Protein Assay Kit (Thermo Scientific). Primary antibodies against HOXA9 (1:1000, Genetex Inc. CA, USA), TGF- $\beta 2$ (1:1000, Santa Cruz Biotechnology, Inc. California USA), TGF- $\beta 3$ (1:1000, Santa Cruz Biotechnology, Inc), MMP2 (1:1000, Genetex Inc), IGF1R $(1 \mu \mathrm{g} / \mathrm{ml}$, Cloud-Clone, TX, USA), FGF2 $(1 \mu \mathrm{g} / \mathrm{ml}$, Cloud-Clone) and $\alpha$-tubulin (1:5000, ProteinTech Group, Cambridge, UK) were used. The 2ndary antibody was conjugated to the membrane and then incubated with horseradish peroxidase. We used the ECL non-radioactive detection system to detect the antibody-protein complexes by the LAS-3000 imaging system (Fujifilm, Tokyo, Japan). The ImageJ software (NIH) was used for quantitative measure.

\section{Statistical analysis}

Quantitative data are expressed as the mean \pm standard error of the mean. To compare the gene expression levels between the covered eye and uncovered fellow eye of the same mouse, we used paired student t-test. For the cellular studies, differences between multiple groups were analyzed using one-way analysis of variance, followed by Tukey's post hoc multiple comparisons test. The relative fold change of RNA expression measured by qPCR was calculated by $2^{-\Delta \Delta \mathrm{CT}}$. Statistical analysis was performed using the Prism software, version 5.0 (GraphPad, Inc., La Jolla, CA, USA). A two-sided $P<0.05$ was considered statistically significant.

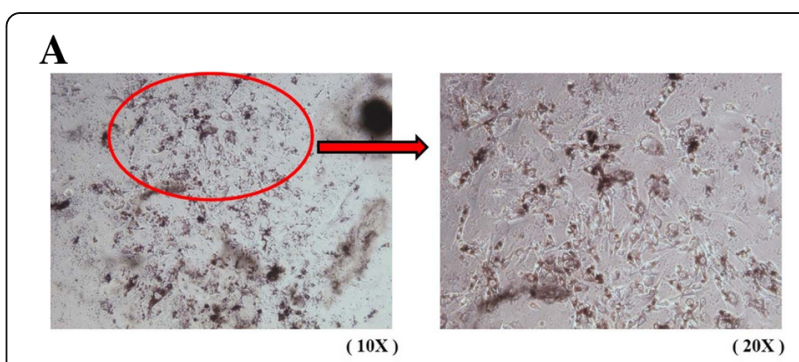

B
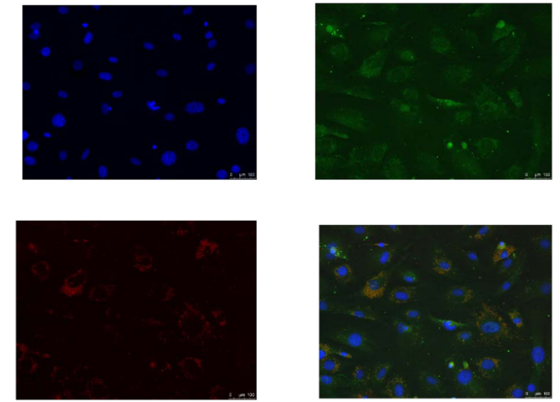

Fig. 2 Isolation and culture of mouse primary RPE cells. a mouse primary RPE cells (b) Immunofluorescent stains confirmed the RPE cells: DAPI (upper left, blue), RPE-65 (upper right, green), ZO-1 (lower left, red) and merge (lower right). Scale bar: $100 \mu \mathrm{m} .20 \times$ magnification 


\section{Results}

Human methylation study for pre-school children

The mean of SE in all pre-school children was 0.90D. Since a negative SE is uncommon at this age, we particularly checked 8 children whose SE values appeared to be outliers (more negative than -2D). Among these 8 myopic children, 7 had hypomethylation but one had hypermethylation at the HOXA9 gene.

\section{Increased HOXA9 expression in myopic eyes in the FDM animals}

We measured HOXA9 RNA levels in the retina of FDM mice $(n=9)$ by real-time PCR. The expression levels (indicated by delta $\mathrm{Ct}$ ) in the retina of myopic eyes were significantly higher ( $p=0.029$ by paired $\mathrm{t}$-test) than the uncovered fellow eyes (Fig. 1). The covered myopic eyes had a higher retinal HOXA9 level by 2.65 -fold when compared with the fellow normal eyes. Due to the scarcity of cells in the sclera, we did not have sufficient RNA quantity to measure HOXA9 expression in the sclera. We also did not collect RPE cells from FDM mice because the sclera and RPE cannot be collected simultaneously from a same eyeball.

\section{miR-328 promotes HOXA9}

Although no particular cell model can be used to test myopia development, the RPE cells have been implicated to play a role in myopia [34]. The RPE cells can secrete several growth factors that have been demonstrated to be associated with eyeball elongation [34]. We have shown that over-expression of miR-328 is a risk for myopia $[2,15]$ and PAX6 may have a link with HOXA9, and therefore we tested whether miR-328 can affect HOXA9 expression in both human and mouse RPE cells. To confirm that we successfully cultured mouse primary RPE cells (Fig. 2a), RPE-specific markers RPE-65 [32] and ZO-1 [33] were demonstrated in the mouse cells by the immunocytochemistry staining (Fig. 2b). We then showed that miR-328 dose-dependently increased HOXA9 expression in ARPE-19 and mouse primary RPE cells, while miR-328 suppressed PAX6 levels (Fig. 3a and b).

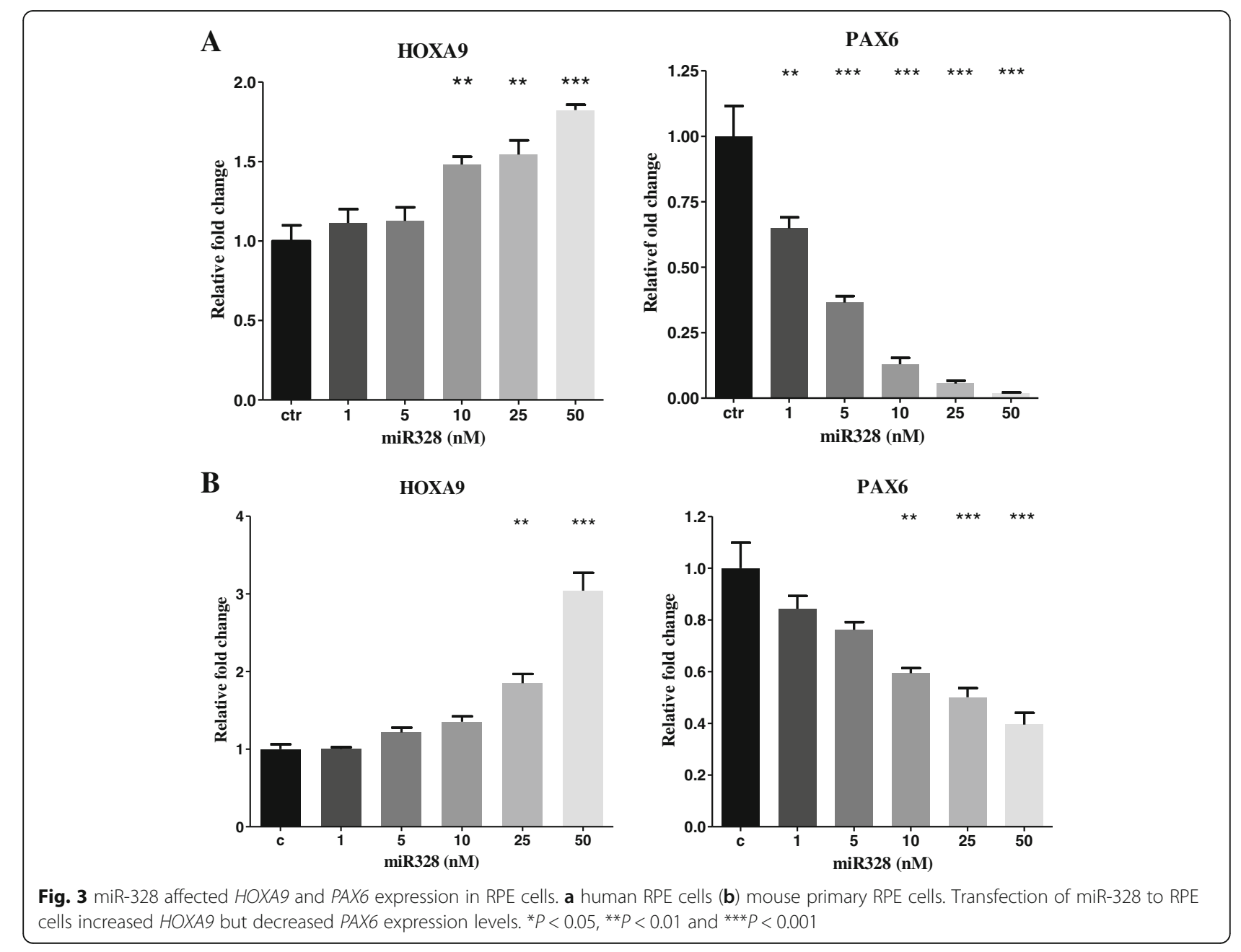




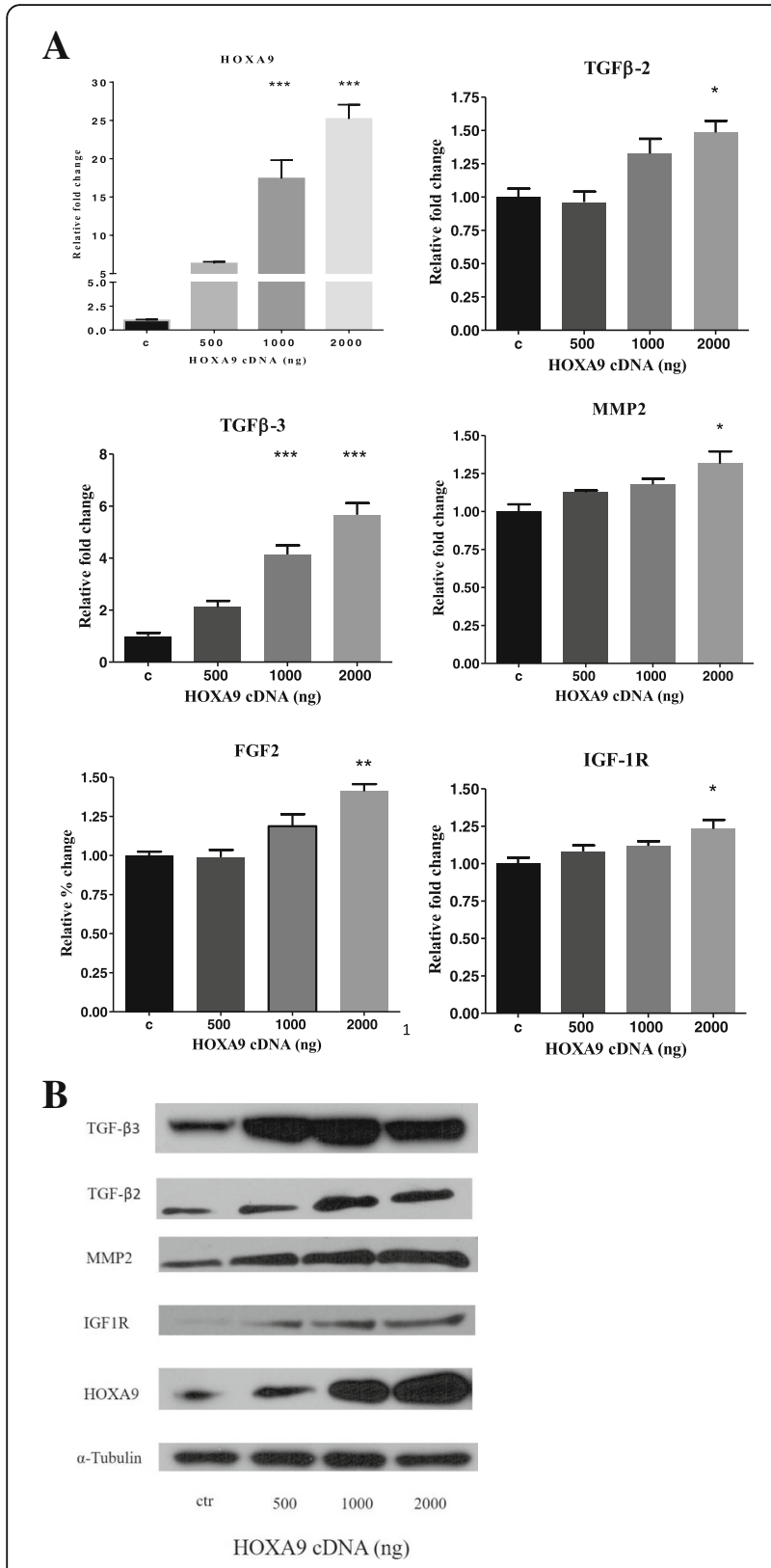

C

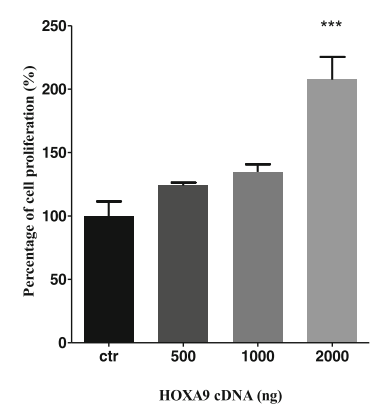

D

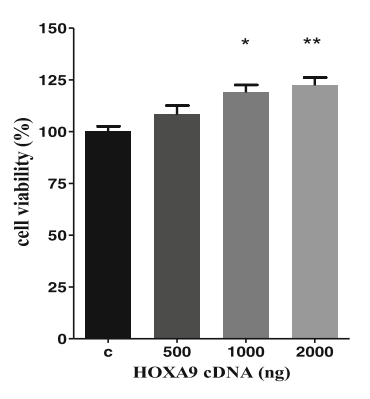

Fig. 4 HOXA9 increased pro-myopia markers and PRE cells. Transfection of HOXA9 plasmid to mouse primary RPE increased (a and b) RNA and protein levels of HOXA9, TGF- $\beta 2$, TGF- $\beta 3, M M P 2$, FGF2 and IGFIR, (c and $\mathbf{d}$ ) the RPE proliferation and viability in a dose-dependent manner ${ }^{*} P<0.05,{ }^{*} P<0.01$ and ${ }^{* * *} P<0.001$.

\section{The effect of over-expression of HOXA9 on RPE cells}

The mouse primary RPE cells were further used to test for the role of over-expressed HOXA9 in myopia development. Although there is no specific molecular marker for myopia, several molecules have been reported to be associated with myopia, which include TGF- $\beta$ [24], FGF2 [35], IGF signaling [36, 37], $\operatorname{HGF}[38,39]$ and MMP2 [40, 41]. Therefore, we tested whether alteration of HOXA9 expression can affect these potential myopia markers. In the mouse RPE cells transfected with HOXA9 cDNA, TGF- $\beta 3$ was significantly increased, followed by TGF- $\beta 2$ while TGF- $\beta 1$ level was not affected (Fig. $4 \mathrm{a}$ and b, data on TGF- $\beta 1$ are not shown). FGF2 and IGF1R expression levels were also dose-dependently increased by HOXA9. MMP2 that is consistently shown to be elevated in myopic animal models was substantially up-regulated by $H O X A 9$. However, over-expression of HOXA9 had no significant influence on IGF1 or HGF expression (data not shown). Furthermore, HOXA9 increased the RPE proliferation and viability in a dosedependent manner (Fig. 4c and d).

\section{Discussion}

HOXA9 is a transcription factor and its function in the eyes has not been reported. Our data implied that HOXA9 may play a role in myopia development. Using a FDM myopic model, we first showed that HOXA9 expression level was significantly higher in the myopic eyes than the fellow normal eyes. Among 8 pre-school children with SE less than -2D, 7 had hypomethylation at HOXA9 which suggested that over-expressed HOXA9 could be a risk factor for early onset myopia. Our cellular studies further demonstrated that an increase of HOXA9 could increase expression in several pro-myopic genes including TGF- $\beta$, FGF2, IGF1R and MMP2 genes.

The $H O X$ genes are a subset of homeobox genes which regulate the development of anatomical structures. There are four HOX gene clusters (HOXA, HOXB, HOXC and $H O X D)$ in humans. The regulation of $H O X$ genes is highly complex, which includes microRNA, DNA methylation and histone modification. The HOXA9 gene encodes a DNA-binding transcription factor which may regulate gene expression, morphogenesis, and differentiation. The HOXA9 gene is of particular interest from a hematopoietic perspective as its dysfunction has been implicated in acute myeloid leukemia [42]. Our data is the first to suggest that HOXA9 may affect myopia development via multiple 
mechanisms including myopia-related genes and RPE proliferation. Although our findings are intriguing, more studies are needed to confirm the role of HOXA9 in myopia development.

It has been indicated that retino-scleral signaling cascade can participate in scleral remodeling during myopic development [43]. The key location of RPE cells makes them plausible conduits for relaying growth regulatory signals originating in the retina to the sclera. In addition, RPE also represents a major source of growth factors and cytokines that can mediate the retinoscleral signaling pathway [34], including IGF1, TGF- $\beta$, FGF, and VEGF [44, 45]. We demonstrated that over-expression of HOXA9 in RPE cells could increase pro-myopia substances including TGF- $\beta$, FGF2, IGF1R and MMP2. However, we acknowledge that our initial discovery of HOXA9 in relation to myopia development was based on small samples of human subjects and animals. Although we show molecular evidence to support HOXA9 as a novel myopia gene, it is warranted that future studies use more animal and human data to validate the role of HOXA9 in myopia.

\section{Conclusion}

To sum up, the present study showed that HOXA9 might be a novel gene that promotes myopia development. Since HOXA9 is a transcription factor, it may directly or indirectly affect expression of pro-myopia genes. In addition, HOXA9 also increases cell proliferation, which may facilitate eyeball elongation during myopia development. However, further studies are warranted to validate our findings.

\section{Abbreviations}

ARPE-19: Human retinal pigment epithelial cell line; AXL: Axial length; FDM: Form deprivation myopia; miR-328: microRNA-328; SE: Spherical equivalent refraction; TGF- $\beta$ : Transforming growth factor- $\beta$

\section{Acknowledgements}

N/A

\section{Availability of data and materials}

The datasets used and/or analysed during the current study are available from the corresponding author on reasonable request.

\section{Authors' contributions}

CLL designed and supervised the study, interpreted the result and wrote the manuscript; PYH conducted the animal and cellular studies, and wrote the manuscript. CN conducted the human study and wrote the manuscript; WJS conducted the human study and wrote the manuscript; NK conducted the human study and wrote the manuscript; PH conducted the human study and wrote the manuscript; SMS designed and supervised the human study, interpreted the result from human study and approved the manuscript; $\mathrm{SHHJ}$ designed and supervised the study, interpreted the result, wrote the manuscript and approved the final manuscript. All authors have read and approved the manuscript, and ensure that this is the case.

\section{Ethics approval and consent to participate}

The study was approved by the National Healthcare Group Domain Specific Review Board (reference number D/09/021) and the SingHealth Centralized
Institutional Review Board (reference number 2009/280/D). Informed written consent was obtained from the parents or legal guardians.

\section{Competing interests}

None of the authors have competing interest.

\section{Publisher's Note}

Springer Nature remains neutral with regard to jurisdictional claims in published maps and institutional affiliations.

\section{Author details}

${ }^{1}$ Department of Ophthalmology, Asia University Hospital, Taichung, Taiwan. ${ }^{2}$ Department of Optometry, College of Medical and Health Science, Asia University, Taichung, Taiwan. ${ }^{3}$ Center for Myopia and Eye Disease, Department of Medical Research, China Medical University Hospital, Taichung, Taiwan. ${ }^{4}$ Bright-Eyes Clinic, Kaohsiung, Taiwan. ${ }^{5}$ Department of Ophthalmology, National University Hospital, Singapore, Singapore. ${ }^{6}$ Saw Swee Hock School of Public Health, National University of Singapore and National University Health System, Singapore, Singapore. ${ }^{7}$ Singapore Institute for Clinical Sciences (SICS), A*STAR, Brenner Centre for Molecular Medicine, Singapore, Singapore. ${ }^{8}$ Singapore Eye Research Institute, Singapore, Singapore. ${ }^{9}$ The Ophthalmology \& Visual Sciences Academic Clinical Program, DUKE-NUS Graduate Medical School, Singapore, Singapore. ${ }^{10} \mathrm{Graduate}$ Institute of Biomedical Sciences, Singapore, Singapore. ${ }^{11}$ Institute of New Drug Development, Singapore, Singapore. ${ }^{12}$ Drug Development Center, China Medical University, Taichung, Taiwan.

Received: 18 June 2018 Accepted: 15 January 2019

Published online: 23 January 2019

References

1. Hsi E, Chen KC, Chang WS, Yu ML, Liang CL, Juo SH. A functional polymorphism at the FGF10 gene is associated with extreme myopia. Invest Ophthalmol Vis Sci. 2013;54:3265-71.

2. Liang $\mathrm{CL}$, Hsi E, Chen KC, Pan YR, Wang YS, Juo SH. A functional polymorphism at 3'UTR of the PAX6 gene may confer risk for extreme myopia in the Chinese. Invest Ophthalmol Vis Sci. 2011;52:3500-5.

3. Liang CL, Wang HS, Hung KS, et al. Evaluation of MMP3 and TIMP1 as candidate genes for high myopia in young Taiwanese men. Am J Ophthalmol. 2006;142:518-20.

4. Verhoeven VJ, Hysi PG, Wojciechowski R, et al. Genome-wide meta-analyses of multiancestry cohorts identify multiple new susceptibility loci for refractive error and myopia. Nat Genet. 2013;45:314-8.

5. Li SM, Li SY, Kang MT, et al. Near work related parameters and myopia in Chinese children: the Anyang childhood eye study. PLoS One. 2015;10: e0134514

6. Miyake M, Yamashiro K, Tabara Y, et al. Identification of myopia-associated WNT7B polymorphisms provides insights into the mechanism underlying the development of myopia. Nat Commun. 2015;6:6689.

7. Simpson CL, Wojciechowski R, Oexle K, et al. Genome-wide meta-analysis of myopia and hyperopia provides evidence for replication of 11 loci. PLoS One. 2014:9:e107110.

8. Guggenheim JA, Northstone K, McMahon G, et al. Time outdoors and physical activity as predictors of incident myopia in childhood: a prospective cohort study. Invest Ophthalmol Vis Sci. 2012;53:2856-65.

9. Jones LA, Sinnott LT, Mutti DO, Mitchell GL, Moeschberger ML, Zadnik K. Parental history of myopia, sports and outdoor activities, and future myopia. Invest Ophthalmol Vis Sci. 2007;48:3524-32.

10. Li SM, Li H, Li SY, et al. Time outdoors and myopia progression over 2 years in Chinese children: the Anyang childhood eye study. Invest Ophthalmol Vis Sci. 2015;56:4734-40

11. Fan Q, Verhoeven VJ, Wojciechowski R, et al. Meta-analysis of geneenvironment-wide association scans accounting for education level identifies additional loci for refractive error. Nat Commun. 2016;7:11008.

12. Weisenberger DJ, Campan M, Long TI, et al. Analysis of repetitive element DNA methylation by MethyLight. Nucleic Acids Res. 2005:33:6823-36.

13. Wu PC, Tsai CL, Wu HL, Yang YH, Kuo HK. Outdoor activity during class recess reduces myopia onset and progression in school children. Ophthalmology. 2013;120:1080-5

14. Cordaux R, Batzer MA. The impact of retrotransposons on human genome evolution. Nat Rev Genet. 2009;10:691-703. 
15. Chen KC, Hsi E, Hu CY, Chou WW, Liang CL, Juo SH. MicroRNA-328 may influence myopia development by mediating the PAX6 gene. Invest Ophthalmol Vis Sci. 2012;53:2732-9.

16. Tang SM, Rong SS, Young AL, Tam PO, Pang CP, Chen LJ. PAX6 gene associated with high myopia: a meta-analysis. Optom Vis Sci. 2014;91: 419-29.

17. Erickson T, French CR, Waskiewicz AJ. Meis1 specifies positional information in the retina and tectum to organize the zebrafish visual system. Neural Dev. 2010;5:22

18. Heine P, Dohle E, Bumsted-O'Brien K, Engelkamp D, Schulte D. Evidence for an evolutionary conserved role of homothorax/Meis1/2 during vertebrate retina development. Development. 2008;135:805-11.

19. Islam MM, Li Y, Luo H, Xiang M, Cai L. Meis1 regulates Foxn4 expression during retinal progenitor cell differentiation. Biol Open. 2013;2:1125-36.

20. Antosova B, Smolikova J, Klimova L, et al. The gene regulatory network of Lens induction is wired through Meis-dependent shadow enhancers of Pax6. PLoS Genet. 2016;12:e1006441.

21. Terrell AM, Anand D, Smith SF, et al. Molecular characterization of mouse lens epithelial cell lines and their suitability to study RNA granules and cataract associated genes. Exp Eye Res. 2015;131:42-55.

22. Shen WF, Rozenfeld S, Kwong A, Kom ves LG, Lawrence HJ, Largman C. HOXA9 forms triple complexes with PBX2 and MEIS1 in myeloid cells. Mol Cell Biol 1999;19:3051-3061.

23. Ko SY, Barengo N, Ladanyi A, et al. HOXA9 promotes ovarian cancer growth by stimulating cancer-associated fibroblasts. J Clin Invest. 2012;122:3603-17.

24. McBrien NA. Regulation of scleral metabolism in myopia and the role of transforming growth factor-beta. Exp Eye Res. 2013;114:128-40.

25. Li LJ, Cheung CY, Ikram MK, et al. Blood pressure and retinal microvascular characteristics during pregnancy: growing up in Singapore towards healthy outcomes (GUSTO) study. Hypertension. 2012;60:223-30.

26. Lin X, Lim IY, Wu Y, et al. Developmental pathways to adiposity begin before birth and are influenced by genotype, prenatal environment and epigenome. BMC Med. 2017;15:50.

27. Pan $\mathrm{H}$, Chen L, Dogra S, et al. Measuring the methylome in clinical samples: improved processing of the Infinium human Methylation450 BeadChip Array. Epigenetics. 2012;7:1173-87.

28. Chen YA, Lemire M, Choufani S, et al. Discovery of cross-reactive probes and polymorphic CpGs in the Illumina Infinium HumanMethylation450 microarray. Epigenetics. 2013;8:203-9.

29. Price ME, Cotton AM, Lam LL, et al. Additional annotation enhances potential for biologically-relevant analysis of the Illumina Infinium HumanMethylation450 BeadChip array. Epigenetics Chromatin. 2013;6:4.

30. Barathi VA, Boopathi VG, Yap EP, Beuerman RW. Two models of experimental myopia in the mouse. Vis Res. 2008;48:904-16.

31. Maminishkis A, Chen $\mathrm{S}$, Jalickee $\mathrm{S}$, et al. Confluent monolayers of cultured human fetal retinal pigment epithelium exhibit morphology and physiology of native tissue. Invest Ophthalmol Vis Sci. 2006;47:3612-24.

32. Huang J, Possin DE, Saari JC. Localizations of visual cycle components in retinal pigment epithelium. Mol Vis. 2009;15:223-34.

33. Konari K, Sawada N, Zhong $Y$, Isomura H, Nakagawa T, Mori M. Development of the blood-retinal barrier in vitro: formation of tight junctions as revealed by occludin and ZO-1 correlates with the barrier function of chick retinal pigment epithelial cells. Exp Eye Res. 1995;61: 99-108.

34. Zhang Y, Wildsoet CF. RPE and choroid mechanisms underlying ocular growth and myopia. Prog Mol Biol Transl Sci. 2015;134:221-40.

35. An J, Hsi E, Zhou X, Tao Y, Juo SH, Liang CL. The FGF2 gene in a myopia animal model and human subjects. Mol Vis. 2012;18:471-8.

36. Metlapally R, Ki CS, Li YJ, et al. Genetic association of insulin-like growth factor-1 polymorphisms with high-grade myopia in an international family cohort. Invest Ophthalmol Vis Sci. 2010;51:4476-9.

37. Zhuang W, Yang P, Li Z, et al. Association of insulin-like growth factor-1 polymorphisms with high myopia in the Chinese population. Mol Vis. 2012; 18:634-44.

38. Veerappan S, Pertile KK, Islam AF, et al. Role of the hepatocyte growth factor gene in refractive error. Ophthalmology 2010;117:239-245 e231-232.

39. Yanovitch T, Li YJ, Metlapally R, Abbott D, Viet KN, Young TL. Hepatocyte growth factor and myopia: genetic association analyses in a Caucasian population. Mol Vis. 2009;15:1028-35.
40. Jia Y, Hu DN, Zhu D, et al. MMP-2, MMP-3, TIMP-1, TIMP-2, and TIMP-3 protein levels in human aqueous humor: relationship with axial length. Invest Ophthalmol Vis Sci. 2014;55:3922-8.

41. Siegwart JT Jr, Norton $\Pi \mathrm{T}$. The time course of changes in mRNA levels in tree shrew sclera during induced myopia and recovery. Invest Ophthalmol Vis Sci. 2002;43:2067-75.

42. Nakamura T, Largaespada DA, Lee MP, et al. Fusion of the nucleoporin gene NUP98 to HOXA9 by the chromosome translocation $\mathrm{t}(7 ; 11)(\mathrm{p} 15 ; \mathrm{p} 15)$ in human myeloid leukaemia. Nat Genet. 1996;12:154-8.

43. McBrien NA, Gentle A. Role of the sclera in the development and pathological complications of myopia. Prog Retin Eye Res. 2003:22:307-38.

44. Rymer J, Wildsoet CF. The role of the retinal pigment epithelium in eye growth regulation and myopia: a review. Vis Neurosci. 2005;22:251-61.

45. Strauss 0 . The retinal pigment epithelium in visual function. Physiol Rev. 2005;85:845-81.
Ready to submit your research? Choose BMC and benefit from:

- fast, convenient online submission

- thorough peer review by experienced researchers in your field

- rapid publication on acceptance

- support for research data, including large and complex data types

- gold Open Access which fosters wider collaboration and increased citations

- maximum visibility for your research: over $100 \mathrm{M}$ website views per year

At BMC, research is always in progress.

Learn more biomedcentral.com/submissions 